\title{
Effect of micropore size distribution on phenol adsorption on steam activated carbons
}

\author{
Ewa Lorenc-Grabowska ${ }^{1}$
}

Received: 14 October 2015/Revised: 25 November 2015/Accepted: 7 December 2015/Published online: 18 December 2015

(C) The Author(s) 2015. This article is published with open access at Springerlink.com

\begin{abstract}
The adsorption of phenol on microporous activated carbons (ACs) produced in laboratory from polyethyleneterephtalate (PET), furfuryl alcohol (PFA), polyacrylonitrile (PAN) and anthracene oil pitch (ASN) have been studied. The ACs have been obtained by carbonization and subsequent steam activation at $850^{\circ} \mathrm{C}$ to $50 \%$ burn off. For comparison, commercial activated carbons from coconut shell, and CWZ 22 carbon have been applied. All studied ACs are predominantly microporous and have neutral or basic surface characteristics. The pseudo second kinetic model and Langmuir equation were found to fit the experimental data very well. A very good correlation between the volume of pores with a width smaller than $1.4 \mathrm{~nm}\left(\mathrm{~V}_{1.4}\right)$ and the volume of phenol calculated from Langmuir monolayer capacity $\left(\mathrm{q}_{\mathrm{m}}\right)$ was found. Based on that, it can be concluded that the phenol adsorption is governed mainly by micropore filling through the $\pi-\pi$ dispersion interaction in micropores smaller than double molecular diameter of phenol.
\end{abstract}

Keywords Phenol · Activated carbons · Adsorption · Pore size distribution

Electronic supplementary material The online version of this article (doi:10.1007/s10450-015-9737-x) contains supplementary material, which is available to authorized users.

Ewa Lorenc-Grabowska

ewa.lorenc-grabowska@pwr.edu.pl

1 Department of Polymer and Carbonaceous Materials, Faculty of Chemistry, Wrocław University of Technology, Gdańska 7/9, 50-344 Wrocław, Poland

\section{Introduction}

Phenol is a common water contamination that can be obstacle even at low concentration hence its efficient removal is a subject of a great interest. Additionally it is a well-known compound that serves as a model molecule used for characterization of adsorptive properties of different materials. Hence there is lot of papers that deal with phenols (Ps) adsorption however only few of them give an answer where the adsorption capacity come from (Mattson et al. 1969; Moreno-Castilla et al.1995; Radovic et al.1997; Hsieh and Teng 2000; Salame and Bandosz 2003; Terzyk 2003; Fierro et al. 2008; Liu et al. 2010). Generally three mechanisms of phenolic compounds adsorption are considered: the $\pi-\pi$ dispersion interaction, the electron-donor-acceptor complex formation and the hydrogen-bond formation (Mattson et al. 1969; Terzyk 2003; Dąbrowski et al. 2005). The first mechanism is based on the dispersion forces between the $\pi$ electrons of phenol ring and the $\pi$ electron of the graphene layer in the activated carbon. The second mechanism proposes the formation of donor-acceptor complex between the surface electron donor groups (e.g. carbonyls) and the aromatic ring of phenol that acts as the acceptor. In the third case the hydrogen of hydroxyl groups of phenol is involved in an intracomplex hydrogen bond with surface oxygen complex.

The adsorption capacity of adsorbent toward phenol is also strongly dependent on the chemical characteristics of adsorbing material that might be expressed as heteroatoms functional group density on the surface. It has been proved that the phenols adsorption from aqueous solution on oxidized activated carbons is diminished due to the solvent effect (Nevskaia et al. 1999; Franz et al. 2000; Huang et al. 2008), therefore for the removal of weak acids like phenol, activated carbons (ACs) with basic surface characteristic are considered as the most appropriate. Also, the presence of 
nitrogen functionalities influences the mechanism of phenolic compounds adsorption. Its presence increases the basicity of carbon surface that enhances the affinity of phenol toward ACs surface (Lorenc-Grabowska et al. 2013).

It is well known that the porosity of carbonaceous material is also a critical factor in adsorption processes of organic compounds from liquid phase (Mattson and Mark 1971) however there are limited studies that deal directly with the correlation between pore size distribution and adsorption capacity toward organic compound. For example Caturla et al. (1988) have reported that when narrow micropores dominate in the porous texture, the adsorption of phenolic compound correlates with the BET surface area while for carbon with predominant contribution of wider pores, the surface properties influence the adsorption of phenol as well. Daifullah and Girgis (1998) reported that the main factor that determines phenolic compounds adsorption is the pore size distribution (PSD) of adsorbent. In other work (Hsieh and Teng 2000) a strong relationship between the adsorption capacity and the adsorption energy which is micropore size distribution dependent, was demonstrated. Also Hu and Srinivasan (2001) or Juang et al. (2001) correlated the adsorption capacity of different ACs toward phenol with micropore volume. Nevertheless none of the work specifies the size of micropore width in which the adsorption takes place. The development in porous texture characterization methods allows to undertake the studies concerning the impact of pore size distribution on the adsorption capacity. For example, the adsorption of trichloroethane and methyl tertiarybutyl ether was correlated with the micropores about 1.3-1.8 times larger in size than the kinetic diameter of the target adsorbates ( $\mathrm{Li}$ et al. 2002). In other work the adsorption of 4,6-dimethyldibenzothiophene (DMDB) was found to be governed by pore with a width corresponding to DMDB molecule size (Seredych et al. 2010). In our previous work a correlation between the adsorption capacity of ACs and the volume of pores with sizes smaller than $1.4 \mathrm{~nm}$ was reported for phenol and p-chlorophenol (Lorenc-Grabowska et al. 2010; Lorenc-Grabowska and Rutkowski 2014).

The main object of this work is to elucidate the role of porosity in the mechanism of phenol adsorption on activated carbons with different background. Due to the fact that phenol is a weak acid and to avoid strong solvent competition effect, for this studies the carbon with neutral or slightly basic surface, low oxygen content but different pore size distribution was selected.

\section{Experimental}

\subsection{Materials}

Two commercial ACs produced by Gryfscand (CS, CWZ) and four laboratory made carbons (PET, PAN, PFA, ASN) were selected for the adsorption test. All carbons were steam activated. The CS carbon is made from coconut shell, the CWZ carbon is wood-based. The PAN, PET and PFA are ACs obtained by carbonization at $870{ }^{\circ} \mathrm{C}$ and subsequent steam activation at $850{ }^{\circ} \mathrm{C}$ of polyacrylonitrile (Lorenc-Grabowska et al. 2013), polyethyleneterephtalate (Lorenc-Grabowska et al. 2009) and polyfurfuryl alcohol (Lorenc-Grabowska et al. 2012). In the case of ASN carbon the carbonization at $900{ }^{\circ} \mathrm{C}$ and activation at $870{ }^{\circ} \mathrm{C}$ of anthracene oil pitch was proceeded by pitch oxidation with mixture of sulfuric/nitric acid (Machnikowska et al. 2011).

\subsection{Characterization of ACs}

The elemental analysis of $\mathrm{C}, \mathrm{H}, \mathrm{N}$ and $\mathrm{S}$ was performed using a Vario III Elemental Analyzer. The oxygen content was calculated by difference. The porous texture was determined from nitrogen adsorption isotherms measured at $77 \mathrm{~K}$ with a NOVA 2200 (Quantachrome). The specific surface area was calculated using the BET method at $\mathrm{pp}_{0}^{-1}$ range: $0.01-0.15$. The amount of nitrogen adsorbed at relatively pressure of $\mathrm{pp}_{0}^{-1}=0.98$ was employed to determine the total pore volume $\left(\mathrm{V}_{\mathrm{T}}\right)$. The micropore volume $\left(\mathrm{V}_{\mathrm{DR}}\right)$ was calculated applying the DubininRadushkevich equation up to $\mathrm{pp}_{0}^{-1} \leq 0.15$. The pore size distribution was determined by means of the density functional theory (DFT) method using Nova Quantachrome software. The $\mathrm{pH}_{\mathrm{PZC}}$ (point of zero charge) of the ACs was determined according to the procedure described by Moreno-Castilla et al. (2000).

\subsection{Sorption of phenol}

The adsorption of phenol from aqueous solutions was carried out at $24{ }^{\circ} \mathrm{C}$ in a static system. The ACs grain size was $0.2-0.5 \mathrm{~mm}$. Speeds of shaking were kept uniform for all experiments. For the adsorption, 0.01-0.2 g of AC was placed into Erlenmeyer flasks and $0.10 \mathrm{dm}^{3}$ of adsorbate solution $\left(150 \mathrm{mg} \mathrm{dm}^{-3}\right)$ was added to each flask. The stoppered flasks were kept in a thermostat shaker bath and were agitated to reach equilibrium. Each set of flasks included two flasks containing blank solutions to check for sorbate volatilization and adsorption on the glass walls. The adsorption isotherms were determined without adding any buffer to control $\mathrm{pH}$ to avoid the presence of a new electrolyte in the system. The $\mathrm{pH}$ of the solution was measured by a digital $\mathrm{pH}$-meter (Accumet Basic, Fisher Scientific) using a combined glass electrode. The concentration of each solute remaining in the water phase was quantified. The phenol concentration was determined using HITACHI U-2800A UV-Vis spectrophotometer at the wavelength of $270 \mathrm{~nm}$. The basic phenol characteristics are given in Table 1. 
Table 1 Phenol

physicochemical characteristics

\begin{tabular}{lll}
\hline & Phenol $(\mathrm{P})$ & Molecule dimension (nm) \\
\hline Molar mass $\left(\mathrm{g} \mathrm{mol}^{-1}\right)$ & 94.11 & \\
Solubility $\left(\mathrm{g} \mathrm{dm}^{-3}\right)$ & 80 & \\
$\mathrm{pK}_{\mathrm{a}}$ & 9.98 & \\
$\lambda(\mathrm{nm})$ & 210 & \\
$\sigma\left(\mathrm{nm}^{2}\right)$ & 0.437 & \\
Molecular volume $\left(\mathrm{nm}^{3}\right)$ & 0.162 & \\
\hline
\end{tabular}

Table 2 Basic characteristics of studied activated carbons

\begin{tabular}{|c|c|c|c|c|c|c|}
\hline & PAN & PET & PFA & ASN & CS & $\mathrm{CWZ}$ \\
\hline \multicolumn{7}{|c|}{ Ultimate analysis (wt\%, dry, ash free basis) } \\
\hline $\mathrm{C}$ & 87.16 & 95.04 & 97.08 & 91.93 & 92.29 & 96.46 \\
\hline $\mathrm{H}$ & 2.39 & 1.88 & 1.30 & 0.99 & 2.99 & 0.11 \\
\hline $\mathrm{N}$ & 7.42 & 0.08 & 0.03 & 1.47 & 0.40 & 0.30 \\
\hline S & 0.00 & 0.03 & 0.01 & 0.54 & 0.30 & 0.04 \\
\hline $\mathrm{O}$ & 3.03 & 2.97 & 1.58 & 5.07 & 4.02 & 3.09 \\
\hline $\mathrm{pH}_{\mathrm{PZC}}$ & 8.8 & 7.3 & 7.6 & 6.2 & 7.7 & 8.3 \\
\hline \multicolumn{7}{|c|}{ Proximate analysis (wt\%) } \\
\hline Moisture & 1.43 & 0.5 & 0.2 & - & 5.90 & 6.99 \\
\hline Ash & 0.36 & 0.0 & 0.0 & 0.49 & 3.30 & 3.28 \\
\hline \multicolumn{7}{|c|}{ Porous texture parameters } \\
\hline $\mathrm{S}_{\mathrm{BET}}\left(\mathrm{m}^{2} \mathrm{~g}^{-1}\right)$ & 730 & 1524 & 1308 & 1117 & 1499 & 970 \\
\hline $\mathrm{V}_{\mathrm{T}}\left(\mathrm{cm}^{3} \mathrm{~g}^{-1}\right)$ & 0.302 & 0.607 & 0.602 & 0.478 & 0.697 & 0.434 \\
\hline $\mathrm{V}_{\mathrm{DR}}\left(\mathrm{cm}^{3} \mathrm{~g}^{-1}\right)$ & 0.286 & 0.590 & 0.505 & 0.436 & 0.540 & 0.343 \\
\hline $\mathrm{V}_{\mathrm{DR}} / \mathrm{V}_{\mathrm{T}}\left(\mathrm{cm}^{3} \mathrm{~g}^{-1}\right)$ & 0.95 & 0.97 & 0.84 & 0.91 & 0.78 & 0.79 \\
\hline
\end{tabular}

\section{Results and discussion}

\subsection{Characteristics of studied activated carbons}

The basic surface characteristics of activated carbons studied in this work has been given in the Table 2. The carbons are of different origin that is distinctly reflected in the elemental composition. The carbon content changes from 87.16 for PAN to 97.08 for PFA. The two carbons are also characterized by, respectively, the highest $(7.42 \mathrm{wt} \%)$ and the lowest $(0.03 \mathrm{wt} \%)$ nitrogen content. Low amount of nitrogen is also found in the PET. The nitrogen in commercial ACs is at level of $0.3-0.4 \mathrm{wt} \%$. Slightly higher nitrogen content (1.47 wt \%) is found in ASN carbon. The nitrogen in this carbon arises from the nitric acid used in the oxidation process. The oxidation step also increased the sulfur content $(0.54 \mathrm{wt} \%)$ in this carbon. The sulfur content at a level of $0.3 \%$ is found in the commercial CS carbon whereas the remaining carbons are characterized by negligible sulfur amount (below $0.05 \mathrm{wt} \%)$. The oxygen in studied carbons is at relatively low level. The highest content is found in ASN (5.07 wt\%) whereas the lowest in PFA (1.58 wt\%) AC. It should be emphasized that selected for the studies carbons are characterized by almost neutral or only slightly basic surface characteristics as the $\mathrm{pH}_{\mathrm{PZC}}$ varies between 6.2 and 8.8 (Table 2). The basic surface characteristics arise mainly from the delocalized electrons of graphene layer hence the $\mathrm{pH}_{\mathrm{PZC}}$ is close to neutral. The presence of nitrogen functional groups (PAN) and alkali mineral contamination (CWZ) increase the basicity of the surface whereas the oxidation with sulphuric and nitric acids in the procedure of ASN production leads to a small fall in the $\mathrm{pH}_{\mathrm{PZC}}$ value. The laboratory made ACs have low mineral matter contamination. The ash content is below $0.5 \mathrm{wt} \%$. The commercial ACs have about 10-fold higher ash content but the amount is considered as low (Table 2).

All studied ACs are microporous. The micropore ratio changes from 0.78 to 0.97 . The volume of micropore and consequently the BET surface area differ significantly. The lowest $\mathrm{S}_{\mathrm{BET}}\left(730 \mathrm{~m}^{2} \mathrm{~g}^{-1}\right)$ and micropore volume $(0.302$ $\left.\mathrm{cm}^{3} \mathrm{~g}^{-1}\right)$ is found for PAN. The highest micropore volume $\left(0.590 \mathrm{~cm}^{3} \mathrm{~g}^{-1}\right)$ and the highest $\mathrm{S}_{\mathrm{BET}}\left(1524 \mathrm{~m}^{2} \mathrm{~g}^{-1}\right)$ are found in the PET. The CS is characterized by the highest total pore volume and the lowest $\mathrm{V}_{\mathrm{DR}} / \mathrm{V}_{\mathrm{T}}$ ratio (0.78). It should be emphasized that although the PET and PFA carbons have the same total pore volume ( 0.607 vs $0.602 \mathrm{~cm}^{3} \mathrm{~g}^{-1}$ ) they are characterized by different micropore volume and consequently different pore size distribution (Fig. 1). The PET compared to PFA carbon has smaller volume of pore with size less than $1.0 \mathrm{~nm}$ and bigger volume of pore with size bigger than $1.6 \mathrm{~nm}$. With the exception of ASN all carbons are characterized by sharp maximum at pore width $1-1.4 \mathrm{~nm}$. The ASN carbon is characterized be bimodal shape with maximum at $0.6-0.8 \mathrm{~nm}$ and at $1.2-1.4 \mathrm{~nm}$. The PFA and CWZ carbons have smaller volume of wider micropore and small mesopore volume compared to PET and CS carbon whereas the ASN is characterized by the highest volume of pore with size smaller than $1.0 \mathrm{~nm}$.

\subsection{Kinetics of phenol adsorption}

The adsorption of phenol on studied ACs is shown in Fig. 2. The process is very rapid in the initial period of adsorption. Over $50 \%$ of the equilibrium sorption capacity is obtained in the first hours of adsorption in the case of PET, PFA, ASN and CWZ carbon while in the case of PAN and CS it takes 

studied ACs determined by DFT method
Fig. 1 Pore size distribution of
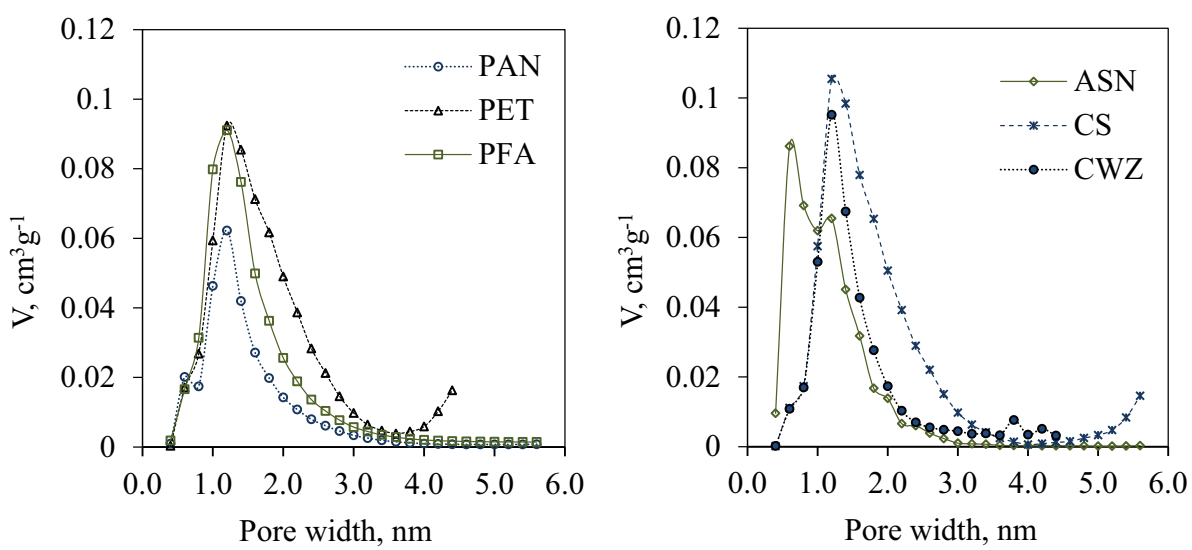

Fig. 2 Phenol adsorption versus time on studied ACs; $\mathrm{C}_{\mathrm{o}}=150 \mathrm{mg} \mathrm{dm}^{-3}$; $\mathrm{V}=0.10 \mathrm{dm}^{3}$ $\mathrm{m}_{\mathrm{AC}}=0.1050 \mathrm{~g}$

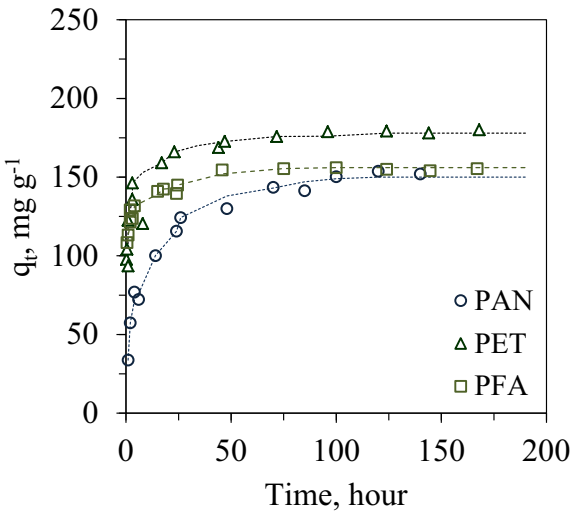

$5 \mathrm{~h}$. The time needed to attained the equilibrium is increasing in the direction: CS $(18 \mathrm{~h})<\mathrm{CWZ}=\mathrm{ASN}(24 \mathrm{~h})<\mathrm{PFA}$ $(45 \mathrm{~h})<$ PET $(52 \mathrm{~h})<$ PAN $(120 \mathrm{~h})$. In uniform experimental condition, the equilibrium time is usually related with the volume of macro- and mesopores that play the role of transporting area. It can be seen that in this work no relationship is found between the mesoporosity and equilibrium time. This is due to the fact that the kinetics is governed not only by the diffusion within the pores. The kinetics of adsorption process in porous material can be divided into three main stages (Weber and Morris 1963). The first is the external diffusion or boundary layer diffusion of solute molecules. The second is the diffusion within the pores of the adsorbent internal structure. The third stage, which is the fastest one, is the adsorption on active sites at the surface. This model is given by Weber and Morris in intraparticle diffusion model. Figure 3 shows the fractional uptake $\mathrm{q}_{\mathrm{t}}$ as a function of $\mathrm{t}^{1 / 2}$ for the adsorption of phenol on studied ACs. It can be clearly seen that the plot are composed of two linear parts. The first part does not pass through point $(0 ; 0)$ indicating that the external layer diffusion control the rate of adsorption. The thickness of the intercept of the plot permits to estimate the boundary layer effect. In our earlier work we have observed the influence of ACs' heteroatom content on the rate of the movement of dissolved molecules in boundary of solution. The lower heteroatoms content and ash contamination the bigger the boundary layer effect (Lorenc-Grabowska and Rutkowski 2014). In this work the thickness of the boundary layer $\left(\mathrm{C}_{\mathrm{I}}\right)$ (Table 3 ) decreases in direction: $\mathrm{PFA}>\mathrm{PET}>\mathrm{CWZ}>\mathrm{ASN}=\mathrm{CS}>\mathrm{PAN}$ whereas the heteroatoms content decreases in direction $\mathrm{PFA}>\mathrm{PET}>\mathrm{CWZ}>\mathrm{CS}>\mathrm{ASN}>\mathrm{PAN}$. The PAN is characterized by the highest contribution of heteroatoms $\mathrm{O}+\mathrm{N}(10.45 \mathrm{wt} \%)$ whereas PFA has the lowest $\mathrm{O}+\mathrm{N}$ content (1.61 wt\%). In the case of carbon CWZ, CS and ASN additional influence of mineral impurities is also observed. Based on that, it can be concluded that indeed the movement in the boundary layer of phenol molecules dissolved in water is related with the hydrophilicity of the adsorbent. The surface of ACs that does not contain hydrophilic groups is not very attractive to water molecule. A consequence of this is a large boundary layer effect due to higher external resistance.

The next step in the adsorption is the intraparticle diffusion that usually occurs in two stages. The adsorbate molecules enter the transporting pores, that is described by the first part of the plot (I) and then, usually more slowly, penetrate smaller pores where the final adsorption takes place, the second part of the plot (II). It can be observed that the slope of the part corresponding to adsorption in smaller pores $\left(\mathrm{k}_{\mathrm{II}}\right)$ is lower than that corresponding to adsorption in 
Fig. 3 Intraparticle diffusion model on studied ACs

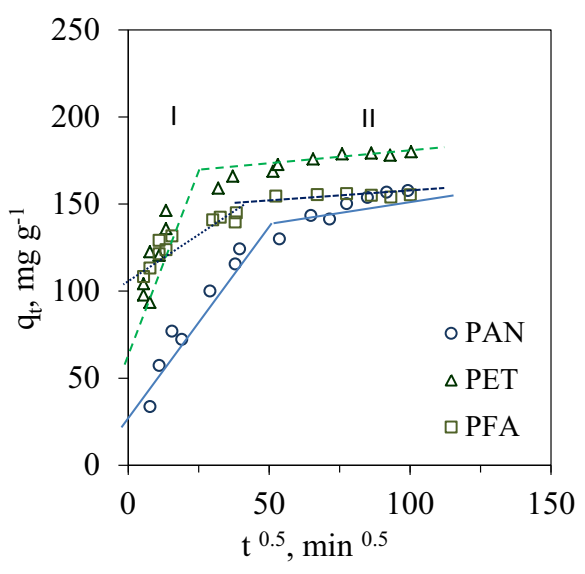

Table 3 Parameters of intraparticle diffusion models of phenol adsorption on ACs

\begin{tabular}{lllllll}
\hline & PAN & PET & PFA & ASN & CS & CWZ \\
\hline $\mathrm{q}_{\mathrm{e} \text { exp }}\left(\mathrm{mg} \mathrm{g}^{-1}\right)$ & 158 & 160 & 158 & 230 & 139 & 90 \\
Intraparticle model & & & & & & \\
$\mathrm{k}_{\mathrm{pI}}\left(\mathrm{mg} \mathrm{g}^{-1} \mathrm{~min}^{-1 / 2}\right)$ & 2.47 & 1.34 & 0.90 & 6.99 & 3.58 & 1.09 \\
$\mathrm{C}_{\mathrm{I}}$ & 27 & 52 & 113 & 30 & 30 & 45 \\
$\mathrm{R}^{2}$ & 0.947 & 0.639 & 0.836 & 0.926 & 0.978 & 0.984 \\
$\mathrm{k}_{\mathrm{pII}}\left(\mathrm{mg} \mathrm{g}^{-1} \mathrm{~min}^{-1 / 2}\right)$ & 0.61 & 0.27 & 0.12 & 0.65 & 0.38 & 0.37 \\
$\mathrm{C}_{\mathrm{II}}$ & 102 & 155 & 145 & 186 & 103 & 72 \\
$\mathrm{R}^{2}$ & 0.919 & 0.843 & 0.867 & 0.756 & 0.880 & 0.804 \\
\hline
\end{tabular}

transporting pores $\left(\mathrm{k}_{\mathrm{I}}\right)$. For all carbons studied in this work the slope of the second part of plot is the smallest and nearly parallel to $\mathrm{x}$ axis indicating that intraparticle diffusion into the micropores is the rate-controlling step.

\subsection{Equilibrium adsorption of phenol}

The processes of phenol adsorption were carried out in unbuffered condition. Taking into account the $\mathrm{pH}$ of solution after the adsorption, that varied between 7.0 and 8.3 , the electrostatic forces do not influence the adsorption processes on studied carbon. The adsorption isotherms for phenol on the ACs studied in this work are shown in Fig. 4. According to Giles classification, the isotherms belong to the L type for the CS and CWZ whereas for PAN, PET, PFA and ASN carbons the type $\mathrm{H}$ is observed. The L class of isotherms is commonly reported for the adsorption of phenols from aqueous solution (Daifullah and Girgis 1998; Ho et al. 1998; Juang et al. 2001; Kilic et al. 2011; Kuśmierek et al. 2014). This is the case when no strong competition between the adsorbate and the solvent for occupying the adsorption sites is observed. The $\mathrm{H}$ type is observed in systems were strong affinity of adsorbate's molecules toward carbon surface, at low adsorbate's concentration, appears. This type of interaction is relatively unique in case of phenol adsorption from water. The PFA and PET activated carbons are characterized by very low oxygen content that eliminate the competition between phenol and water for adsorption site. The H-type isotherm in the case of PAN and ASN indicates that the nitrogen presence enhances the affinity between the AC surface and phenol molecule.

The Langmuir and Freundlich models were used to interpret the obtained data. This is due to the fact that these models are the simplest ones but directly give information on the adsorption capacity or heterogeneity factor that allows to study the mechanism of organic compounds adsorption. The equation's parameters of systems studied in this work are given in Table 4, whereas the Langmuir and Freundlich equations' description are given in details in supplementary files (Table S1). The comparison of the $\mathrm{R}^{2}$ values of the linearized form of both equations indicates that the Langmuir model $\left(\mathrm{R}^{2}: 0.970-0.998\right)$ yields a better fit than the Freundlich model ( $\left.\mathrm{R}^{2}: 0.822-0.968\right)$ and can be applied to entire region of phenol concentration. The Langmuir monolayer capacity increases as follows: $\mathrm{CWZ}>\mathrm{CS}>\mathrm{PAN}>\mathrm{PFA}>\mathrm{PET}>\mathrm{ASN}$. It can be observed that large surface area and a big micropore volume are not sufficient to obtained high adsorption capacity adsorbent for phenol removal. The highest Langmuir adsorption capacity $\left(\mathrm{q}_{\mathrm{m}}=303 \mathrm{mg} \mathrm{g}^{-1}\right)$ is observed on ASN that is characterized by $\mathrm{S}_{\mathrm{BET}}=1117 \mathrm{~m}^{2} \mathrm{~g}^{-1}$ and $\mathrm{V}_{\mathrm{DR}}=0.478 \mathrm{~cm}^{3} \mathrm{~g}^{-1}$, whereas activated carbon with highest $\mathrm{S}_{\mathrm{BET}}$ and $\mathrm{V}_{\mathrm{DR}}$ (PET) has $\mathrm{q}_{\mathrm{m}}$ about $100 \mathrm{mg}$ smaller $\left(217 \mathrm{mg} \mathrm{g}^{-1}\right.$ ). The lowest $\mathrm{q}_{\mathrm{m}}$ is found in CWZ with surface area $\left(\mathrm{S}_{\mathrm{BET}}\right)$ over $240 \mathrm{~m}^{2} \mathrm{~g}^{-1}$ bigger than the lowest $\mathrm{S}_{\mathrm{BET}}$ of carbons studied in this work (PAN).

\subsection{On the mechanism of phenol adsorption}

The adsorption capacity of ACs depends on various factors such as porous texture and surface functional groups of adsorbent; the polarity, solubility molecular size of 
Fig. 4 Equilibrium adsorption isotherm of phenol on studied ACs
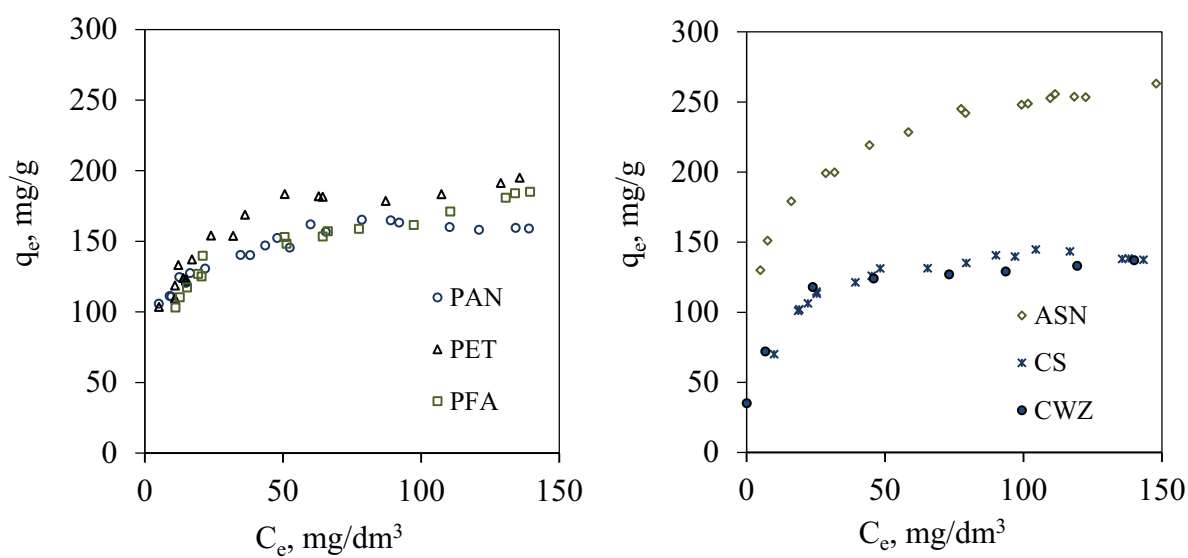

Table 4 Langmuir and Freundlich equation parameters for phenol adsorption on studied ACs

\begin{tabular}{lllllll}
\hline Adsorbent & PAN & PET & PFA & ASN & CS & CWZ \\
\hline Langmuir & & & & & & \\
$\mathrm{q}_{\mathrm{m}}\left(\mathrm{mg} \mathrm{g}^{-1}\right)$ & 167 & 217 & 189 & 303 & 145 & 139 \\
$\mathrm{~b}\left(\mathrm{dm}^{3} \mathrm{~g}^{-1}\right)$ & 0.216 & 0.096 & 0.094 & 0.100 & 0.160 & 0.237 \\
$\theta^{*}$ & 0.640 & 0.391 & 0.404 & 0.706 & 0.207 & 0.401 \\
$\mathrm{R}^{2}$ & 0.998 & 0.998 & 0.978 & 0.970 & 0.998 & 0.996 \\
Freundlich & & & & & & \\
$\mathrm{K}_{\mathrm{f}}\left(\mathrm{mg}^{1-\mathrm{n}} \mathrm{dm}^{3 \mathrm{n}} \mathrm{g}^{-1}\right)$ & 85 & 70 & 66 & 125 & 69 & 57 \\
$\mathrm{n}$ & 0.138 & 0.225 & 0.202 & 0.190 & 0.149 & 0.189 \\
$\mathrm{R}^{2}$ & 0.923 & 0.958 & 0.917 & 0.960 & 0.822 & 0.968 \\
pH of solution after adsorption & $7.9-8.2$ & $6.9-7.4$ & $6.8-7.1$ & $8.1-8.3$ & $7.0-7.3$ & $7.9-8.3$ \\
\hline
\end{tabular}

* Equivalent surface monolayer defined as $\theta=\left(\mathrm{a}_{\mathrm{m}} \sigma \mathrm{N}_{\mathrm{A}}\right) / \mathrm{M}_{\mathrm{w}} \mathrm{S}_{\mathrm{BET}}$, see Table S1 adsorbate, $\mathrm{pH}$ of solution or the presence of other ions in the solution. In this work, the condition of adsorption processes allowed to exclude the impact of electrostatic interaction on the adsorption mechanism. The influence of the surface characteristics on the adsorption can be expressed as the relationship between the adsorption capacity of ACs and heteroatom density. The enhanced water adsorption on polar surface functional group $(\mathrm{O}$ or $\mathrm{N}$ containing) usually leads to a decrease of adsorption capacity with increased heteroatom density on AC surface (Li et al. 2002, Salame and Bandosz 2003; Lorenc-Grabowska et al. 2010). On the other hand the hydrogen bond formation between the hydrogen of phenol's hydroxyl groups requires the surface oxygen or nitrogen complexes. In this work no relationship is observed between the heteroatom density and amount of adsorbed phenol (Fig. 5a). This is due to the fact that the studied ACs carbons are of different origin and some are contaminated with mineral impurities that influence the surface polarity as well. It also permits to reduce the importance of hydrogen bonding in the case of phenol adsorption on non-acidic carbons. As can be seen in Fig. $5 b$ there is also no relationship between the $\mathrm{q}_{\mathrm{m}}$ and the surface area $\mathrm{S}_{\mathrm{BET}}$. This is also reflected in the calculated surface coverage $\theta$ (Table 4 ) that changes from 0.207 to 0.706 and allows to conclude that definitely the surface area is not the factor that rules the carbons adsorption capacity.

The two of the three proposed in literature mechanisms of phenolic compounds adsorption are considered to take place in micropores: the $\pi-\pi$ dispersion interaction are reinforced when adsorption takes place in smaller micropore as micropore filling. This is due to the enhanced adsorption potential occurring from the neighboring graphene walls. On the contrary, the formation of donor-acceptor complex is postulated to occur in wider micropores and mesopores. According to studies of $\mathrm{Hu}$ and Srinivasan (2001) on phenol adsorption, its molecule penetrates the pore with size bigger than $1 \mathrm{~nm}$. Our earlier studies (Lorenc-Grabowska et al. 2013, 2014) have shown that the preferential adsorption of phenol occurs in pore smaller than $1.4 \mathrm{~nm}$. As can be seen on Fig. 5c the phenol adsorption capacity is increasing with increasing volume of pore with size smaller than $1.4 \mathrm{~nm}$. To have a deeper insight into adsorption mechanism, the volume of adsorbed 


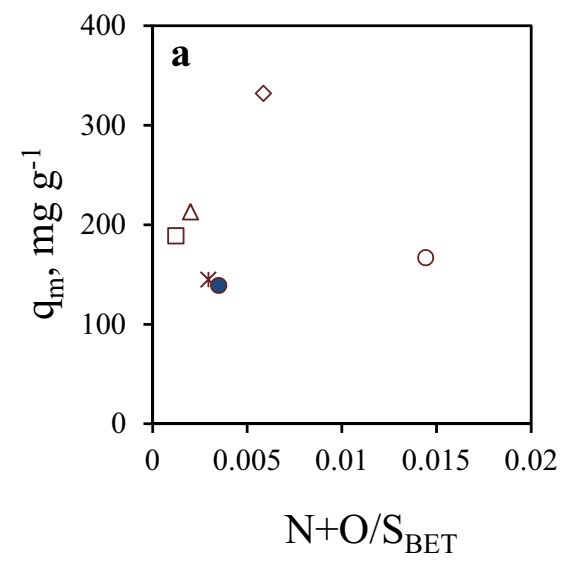

Fig. 5 Relationship between the Langmuir adsorption capacity $\left(\mathrm{q}_{\mathrm{m}}\right)$ and the density of heteroatoms on the surface (a); surface area, $\mathrm{S}_{\mathrm{BET}}$ (b) and volume of pore smaller than $1.4 \mathrm{~nm}$, (c); (white circle) PAN;
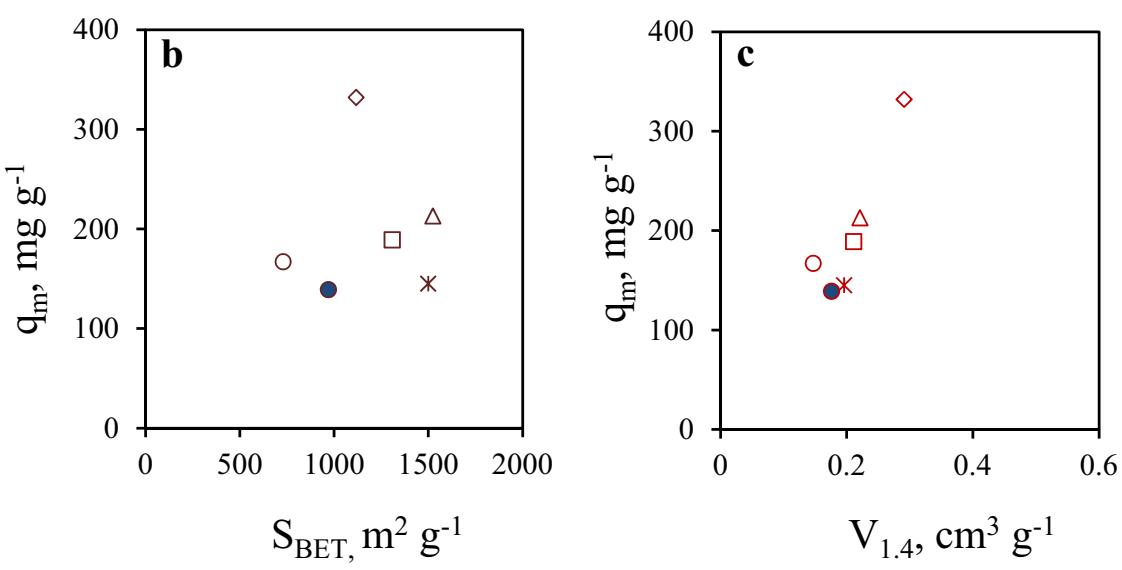

(white triangle) PET; (white square) PFA; (lozenge) ASN; (asterisk) CS; (black circle) $\mathrm{CWZ}$
Fig. 6 Correlation between the volume of pores with different size and volume of adsorbed phenol calculated on the basis of $\mathrm{q}_{\mathrm{m}}$

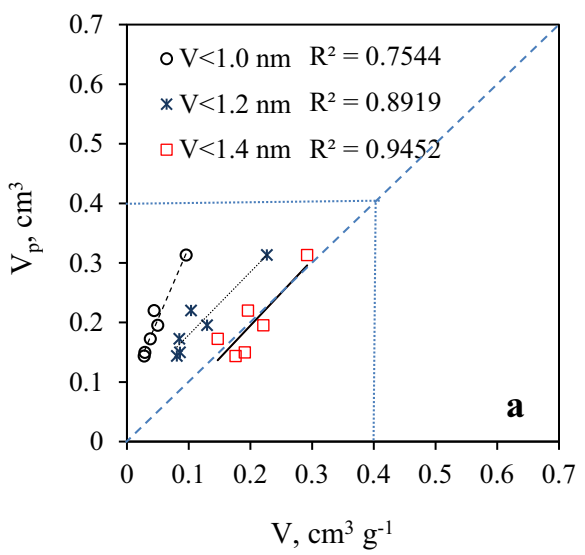

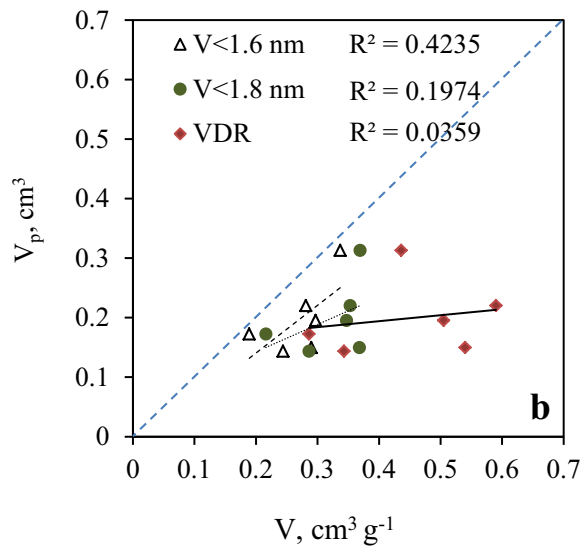

phenol $\left(\mathrm{V}_{\mathrm{p}}\right)$, calculated on the basis of the molecular volume of phenol (Table 1) and Langmuir monolayer adsorption capacity $\left(\mathrm{q}_{\mathrm{m}}\right)$, (Table 4 ) was correlated with volume of micropores with different size (Fig. 6). It can be seen that the correlation coefficient changes from 0.0359 to 0.9452. The highest $R^{2}$ is observed for correlation $V_{p}$ versus $\mathrm{V}_{<1.4}$ (Fig. 6a). What more, the volume of adsorbed phenol is comparable with the volume of pore smaller than $1.4 \mathrm{~nm}$. The ratio of $\mathrm{V}_{\mathrm{p}} / \mathrm{V}_{<1.4}$ changes as follow: 0.78 $(\mathrm{CS})<0.82(\mathrm{CWZ})<0.97$ (PFA) $<1.07 \quad(\mathrm{ASN})<1.12$ $(\mathrm{PET})<1.17$ (PAN). The perfect fit is observed for laboratory made carbon, a slightly worse fit is observed for the commercial ACs. Although in liquid phase adsorption of low molecular weight compounds the overlapping adsorption potentials of opposite walls make the adsorption much stronger in smaller micropore. However in ultramicropores the molecular sieving effect may occur or due to the shape of pores that does not allow the molecules to penetrate into micropores or because the pore width is narrower than the molecular size of the adsorbate (Zhang et al. 2006). Also the presence of some functional group in the microporosity might cause the pore blocking effect and force the phenol molecule to adsorb only in pores with size greater than the size of phenol molecule. (Salame and Bandosz 2003). Due to the fact that the commercial ACs do not give such a good fit a further studies with lower limits of micropore width was conducted. Taking into account phenol molecular size $(0.54-0.46 \mathrm{~nm})$ (Table 1) and the effective molecule diameter $(0.75 \mathrm{~nm})$ calculated from an equation: $\pi r^{2}=\sigma$; the correlation between the volume of micropores with width greater than 0.6 and $0.8 \mathrm{~nm}$ was taken as a measure of the extent of phenol adsorption. The ratio of $\mathrm{V}_{\mathrm{p}} / \mathrm{V}_{0.6-1.4}$ remains almost unchanged 0.78 $(\mathrm{CS})<0.82(\mathrm{CWZ})<0.97(\mathrm{PFA})<1.10(\mathrm{ASN})<1.12$ $(\mathrm{PET})<1.18$ (PAN) whereas the ratio of $\mathrm{V}_{\mathrm{p}} / \mathrm{V}_{0.8-1.4}$ drastically increases: 0.83 (CS) $<0.87 \quad(\mathrm{CWZ})<1.16$ $(\mathrm{PFA})<1.59(\mathrm{ASN})<1.23(\mathrm{PET})<1.37$ (PAN). It can be observe that with the exception of the two commercial ACs the volume of ultra-micropores participates in the phenol adsorption processes. 
The obtained in this work results shows that presences of hydrophilic mineral impurities significantly affect the accessibility of ultra-micropores to the phenol molecules particularly in carbons with small volume of pore with size smaller than $1 \mathrm{~nm}$. The relatively high heteroatoms content observed in ASN and PAN do not give any pore blocking effect and all pores smaller than $1.4 \mathrm{~nm}$ take part in phenol adsorption.

Taking into account the result of this work the upper limit of pore size can be estimated. Phenol adsorb preferentially in pores with size smaller than doubled molecular diameter. The precise definition of the lower limit of pore size still needs to be verified and further studies concerning adsorption in ultra-microporosity should be carried out.

\section{Conclusions}

The adsorptions of phenol on ACs with basic and neutral surface characteristics were carried out. The studied adsorbent varied in heteroatoms content and pore size distribution. The adsorption processes were very fast. After only $5 \mathrm{~h}$ over $50 \%$ of the final adsorption capacity was reached. The equilibrium isotherms were type $\mathrm{L}$ in the case of commercial ACs whereas the $\mathrm{H}$ type was observed for the laboratory made ACs. The calculated Langmuir adsorption capacity varied from 145 to $303 \mathrm{mg} \mathrm{g}^{-1}$.

The boundary layer effect was lower for carbon with higher hydrophility whereas the intraparticle diffusion was the rate controlling step for all studied carbons.

The mineral impurities in the case of commercial ACs influence the mechanism of phenol adsorption.

It was shown that the main mechanism that rules the phenol adsorption is micropore filling in pore with size smaller than $1.4 \mathrm{~nm}$.

Acknowledgments The work was financed by a statutory activity subsidy from the Polish Ministry of Science and Higher Education for the Faculty of Chemistry of Wrocław University of Technology.

\section{Compliance with ethical standards}

Conflict of interest Nothing to declare.

Open Access This article is distributed under the terms of the Creative Commons Attribution 4.0 International License (http://creative commons.org/licenses/by/4.0/), which permits unrestricted use, distribution, and reproduction in any medium, provided you give appropriate credit to the original author(s) and the source, provide a link to the Creative Commons license, and indicate if changes were made.

\section{References}

Caturla, F., Martin-Martinez, J.M., Molina-Sabio, M., RodriguezReinoso, F., Torregrosa, R.: Adsorption of substituted phenols on activated carbon. J. Colloid Interface Sci. 24, 234-528 (1988)
Dąbrowski, A., Podkościelny, P., Hubicki, Z., Barczak, M.: Adsorption of phenolic compounds by activated carbon-a critical rewiev. Chemosphere 58, 1049-1070 (2005)

Daifullah, A.A.M., Girgis, B.S.: Removal of some substituted phenols by activated carbon obtained from agricultural waste. Water Res. 32, 1169-1177 (1998)

Fierro, V., Torne-Fernandez, V., Montane, D., Celzard, A.: Adsorption of phenol onto activated carbons having different textural and surface properties. Microporous Mesoporous Mater. 111, 276-284 (2008)

Franz, M., Arafat, H.A., Pinto, N.G.: Effect of chemical surface heterogeneity on the adsorption mechanism of dissolved aromatics on activated carbon. Carbon 38, 1807-1819 (2000)

Ho, Y.S., McKay, G.A.: Comparison of chemisorption kinetic models applied to pollutant removal on various sorbents. Trans. Inst. Chem. Eng. B 76, 332-340 (1998)

Hsieh, C.T., Teng, H.: Liquid-phase adsorption of phenol onto activated carbons prepared with different activation levels. J. Colloid Interface Sci. 230, 171-175 (2000)

Hu, Z., Srinivasan, M.P.: Mesoporous high-surface-area activated carbon. Microporous Mesoporous Mater. 43, 261-275 (2001)

Huang, J., Huang, K., Liu, S., Lou, Q., Shi, S.: Synthesis, characterization and adsorption behavior of aniline modified polystyrene resin for phenol in hexane and in aqueous solution. J. Colloid Interface Sci. 317, 434-441 (2008)

Juang, R.-S., Tseng, R.-L., Wu, F.-C.: Role of microporosity of activated carbons on their adsorption abilities for phenols and dyes. Adsorption 7, 65-72 (2001)

Kilic, M., Apaydin-Varol, E., Putun, A.E.: Adsorptive removal of phenol from aqueous solution on activated carbon prepared from tobacco residues: equilibrium, kinetics and thermodynamics. J. Hazard. Mater. 189, 397-403 (2011)

Kuśmierek, K., Sankowska, M., Świątkowski, A.: Kinetic and equilibrium studies of simultaneous adsorption of monochlorophenols and chlorophenoxy herbicides on activated carbon. Desalin. Water Treat. 52, 178-183 (2014)

Li, P., Quinlivan, P.A., Knappe, D.R.U.: Effects of activated carbon surface chemistry and pore structure on the adsorption of organic contaminants from aqueous solution. Carbon 40, 2085-2100 (2002)

Liu, Q., Zheng, T., Wang, P., Jiang, J., Li, N.: Adsorption isotherm, kinetic and mechanism studies of some substituted phenols on activated carbon fibers. Chem. Eng. J. 157, 348-356 (2010)

Lorenc-Grabowska, E., Gryglewicz, G., Diez, M.A.: Kinetisc and equilibrium study of phenol adsorption on nitrogen-enriched activated carbons. Fuel 114, 235-243 (2013)

Lorenc-Grabowska, E., Gryglewicz, G., Machnikowski, J., Diez, M.A., Barriocahal, C.: Activated carbons from coal/pitch and polyethylene terephtalate blends for the removal of phenols from aqueous solutions. Energy Fuels 23, 2675-2683 (2009)

Lorenc-Grabowska, E., Gryglewicz, G., Machnikowski, J.: p-chlorophenol adsorption on activated carbons with basic surface characteristics. Appl. Surf. Sci. 256, 4480-4487 (2010)

Lorenc-Grabowska, E., Rutkowski, P.: High basicity adsorbents from solid residue of cellulose and synthetic polymer co-pyrolysis for phenol removal: kinetics and mechanism. Appl. Surf. Sci. 316, 435-442 (2014)

Lorenc-Grabowska, E., Wróbel-Iwaniec, I., Gryglewicz, G: Congo Red removal on mesoporous activated carbons from polyfurfuryl alcohol. In: Proceedings of the Annual Word Conference on Carbon, Pen-drive, ID 902, Cracov, Poland (2012)

Machnikowska, H., Torchała, K., Gryglewicz, G., Machnikowski, J.: Wet oxidation of anthracene oil-based pitch-a way to porous carbons. In: International Conference on Coal Science and Technology, ICCS\&T'2011, Oviedo, Extended Abstracts, CDROM (2011) 
Mattson, J.S., Mark Jr, H.B., Malbin, M.D., Weber Jr, W.J., Crittenden, J.C.: Surface chemistry of active carbon: specific adsorption of phenols. J. Colloid Interface Sci. 31, 116-130 (1969)

Mattson, J.S., Mark Jr, H.: Activated carbon, surface chemistry and adsorption from solution. Dekker, New York (1971)

Moreno-Castilla, C., Lopez-Ramon, M.V., Carrasco-Marin, F.: Changes in surface chemistry of activated carbons by wet oxidation. Carbon 38, 1995-2001 (2000)

Moreno-Castilla, C., Riviera-Utrilla, J., Lopez-Ramon, M.V., CarrascoMarin, F.: Adsorption of some substituted phenols on activated carbons from a bituminous coal. Carbon 33, 845-851 (1995)

Nevskaia, D.M., Santianes, A., Munoz, V., Guerrero-Ruiz, A.: Interaction of aqueous solutions of phenol with commercial activated carbons: an adsorption and kinetic study. Carbon 37, 1065-1074 (1999)

Radovic, L.R., Silva, I.F., Ume, J.I., Menendez, J.A., Leon, Y., Leon, C.A.: An experimental and theoretical study of the adsorption of aromatics possessing electron-withdrawing and electron-donat- ing functional groups by chemically modified activated carbons. Carbon 35, 1339-1348 (1997)

Salame, I.I., Bandosz, T.J.: Role of surface chemistry in adsorption of phenol on activated carbons. J. Colloid Interface Sci. 264, 307-312 (2003)

Seredych, M., Deliyanni, E., Bandosz, T.J.: Role of microporosity and surface chemistry in adsorption of 4,6-dimethyldibenzothiophene on polymer-derived activated carbons. Fuel 89, 1499-1507 (2010)

Terzyk, A.P.: Further insights into the role of carbon surface functionalities in the mechanism of phenol adsorption. J. Colloid Interface Sci. 268, 301-329 (2003)

Weber, W.J., Morris, C.J.: Kinetics of adsorption on carbon from solution. J. Sanit. Eng. Div. 89, 31-60 (1963)

Zhang, X., Li, A., Jiang, Z., Zhang, Q.: Adsorption of dyes and phenol from water on resin adsorbents: effect of adsorbate size and pore size distribution. J. Hazar. Matter. 137, 1115-1122 (2006) 